\title{
Metáforas e gráficos pictórico-esquemáticos de Nigel Holmes Nigel Holme's metaphors and pictorial-schematic charts
}

\author{
Ricardo Cunha Lima
}

visualização de dados, infografia, metáfora visual, linguagem gráfica, visualização de informação

Neste artigo, abordaremos metáforas visuais utilizadas na visualização de dados da infografia do célebre designer Nigel Holmes. Isto foi feito mediante o diálogo com a linguística cognitiva e a retórica visual, pela ótica da teoria de design da informação. Para tanto, nossa abordagem é embasada na teoria das metáforas cognitivas, marcadas pelos estudos de Lakoff e Johnson (1980), e a tradição de estudos de figuras de linguagem visual. Nesta análise utilizamos uma taxonomia de figuras de linguagem pictóricas utilizadas em gráficos estatísticos (LIMA, 2018). Ao analisarmos as metáforas pictóricas utilizadas por Holmes, observamos que este designer tem a tendência a sobrepor elementos pictóricos a elementos esquemáticos em seus gráficos estatísticos. Nós cunhamos esta mescla de modalidades gráficas de gráficos pictórico-esquemáticos. Este uso de elementos pictóricos, muitas vezes, humorísticos sobrepostos a dados numéricos precisos foi duramente combatida por teóricos do design da informação como Edward Tufte, na década de 1980. Estes elementos pictóricos foram chamados de chartjunk. Este termo tem servido como uma crítica à elementos visuais consideradas supérfluos em nome de uma abordagem mais neutra na infografia e visualização de dados. No entanto, procuramos entender a escolha do uso de metáforas visuais por Holmes como uma abordagem que não se limita a uma suposta neutralidade de linguagem gráfica.

data visualization, infographics, visual metaphor, graphic language, information visualization

In this article, the focus is on visual metaphors used in Nigel Holmes' data visualizations present in his infographics. This analysis was accomplished by approaching the theory of cognitive linguistics and visual rhetoric from the point of view of information design. Our study is based on the theory of cognitive metaphors, notably the work of Lakoff and Johnson (1980), and the study of figures of speech in visual language. In this analysis we used a taxonomy of figures of speech for pictorial language in data visualization (LIMA, 2018). When analyzing the pictorial metaphors used by Holmes, we observe that this designer tends to overlap pictorial elements on schematic ones in his statistical charts. We coined this mix of graphic modalities: pictorial-schematic charts (gráficos pictórico-esquemáticos). This use of pictorial elements, often humorous, overlapping precise numerical data was harshly opposed by information design theorists such as Edward Tufte in the 1980s. These pictorial elements were called chartjunk. This term has served as a criticism of visual elements considered superfluous in the name of a more neutral approach to infographics and data visualization. However, we seek to understand Holmes' choice of using visual metaphors as an approach that is not limited to a supposedly neutral graphic language.

Anais do 9 CIDI e 9 CONGIC

Luciane Maria Fadel, Carla Spinillo, Anderson Horta, Cristina Portugal (orgs.)

Sociedade Brasileira de Design da Informação - SBDI Belo Horizonte | Brasil | 2019

ISBN 978-85-212-1728-2
Proceedings of the 9th CIDI and 9th CONGIC Luciane Maria Fadel, Carla Spinillo, Anderson Horta, Cristina Portugal (orgs.)

Sociedade Brasileira de Design da Informação - SBDI Belo Horizonte | Brazil | 2019

ISBN 978-85-212-1728-2 


\section{Introdução}

Uma das funções principais da infografia e visualização de dados é a explicação de um fenômeno ou acontecimento de uma maneira compreensível a um público leigo. Pelo menos essa é a opinião de Nigel Holmes (2001), para quem o termo "infographics" deveria ser substituído por "explanation graphics". No cotidiano do infografista, ele deve levar em conta o que o leitor conhece, para que a informação seja compreendida adequadamente. À primeira vista, uma abordagem literal pode parecer a melhor maneira de se fazer essa aproximação. No entanto, quem já tentou usar apenas descrições literais para explicar algum fenômeno sabe que isso, muitas vezes, é insuficiente. Se a explicação exige conhecimentos pouco familiares à sua audiência, nestes casos, o uso de analogia através de metáforas tem se mostrado eficiente.

Neste artigo, abordaremos metáforas visuais utilizadas na visualização de dados da infografia do célebre designer Nigel Holmes. Isto foi feito mediante o diálogo com a linguística cognitiva e a retórica visual, pela ótica da teoria de design da informação. Para tanto, nossa abordagem é embasada na teoria das metáforas cognitivas, marcadas pelos estudos de Lakoff e Johnson (1980), e a tradição de estudos de figuras de linguagem visual. Nesta análise utilizamos uma taxonomia de figuras de linguagem pictóricas utilizadas em gráficos estatísticos (Lima, 2018).

Ao analisarmos as metáforas pictóricas utilizadas por Holmes, observamos que este designer tem a tendência a sobrepor elementos pictóricos a elementos esquemáticos em seus gráficos estatísticos. Nós cunhamos esta mescla de modalidades gráficas de gráficos pictóricoesquemáticos. Este uso de elementos pictóricos, muitas vezes, humorísticos sobrepostos a dados numéricos precisos foi duramente combatida por teóricos do design da informação como Edward Tufte, na década de 1980. Estes elementos pictóricos foram chamados de chartjunk. Este termo tem servido como uma crítica à elementos visuais consideradas supérfluos em nome de uma abordagem mais neutra na infografia e visualização de dados. No entanto, procuramos entender a escolha do uso de metáforas visuais por Holmes como uma abordagem que não se limita a uma suposta neutralidade de linguagem gráfica.

\section{A infografia de Nigel Holmes}

O trabalho de Holmes tem sido muito influente e controverso. Em 1977, ele começou a trabalhar com Walter Bernard, diretor de arte responsável por seu redesign da revista Time. Bernard valorizou infográficos visualmente vibrantes que, por sua vez, influenciaram outras mídias impressas (Lupton \& Miller, [1996] 2011:145). Os gráficos estatísticos que Holmes criava nessa época eram caracteristicamente pictóricos e valorizavam o humor como uma forma de aproximação do leitor a dados pouco familiares. Inicialmente, essa abordagem não foi bem recebida pela própria revista Time, por isso, o apoio de Bernard foi essencial no enfrentamento aos editores resistentes aos gráficos criados por Holmes. Mas, assim que ficou claro que os leitores gostavam do que estava sendo feito, os editores abraçaram a linguagem gráfica de Holmes (Heller, 2006).

Uma das características do seu trabalho das décadas de 1970 e 1980 foi o uso extensivo de figuras de linguagem pictóricas. Segundo o próprio Holmes, sua motivação ao usar metáforas e a linguagem figurada foi o fato de que os escritores das matérias tinham dificuldade de explicar conceitos complicados para os designers. Como Holmes não era bem familiarizado com os conceitos financeiros e comerciais abordados, os escritores utilizando metáforas nas explicações. Estas analogias facilitam a compreensão e Holmes, em contrapartida, também criava metáforas visuais para enriquecer o sentido de seus infográficos. Este processo o levou a concluir que as metáforas visuais acessíveis eram a forma ideal de explicar aquele tipo de conteúdo para os leitores da Time (Heller, 2006). Na figura 1, vemos que Holmes utilizava uma linguagem cartunesca para representar dados estatísticos sobre a variação no preço da gasolina.

Anais do 9 Congresso Internacional de Design da Informação । CIDI 2019 


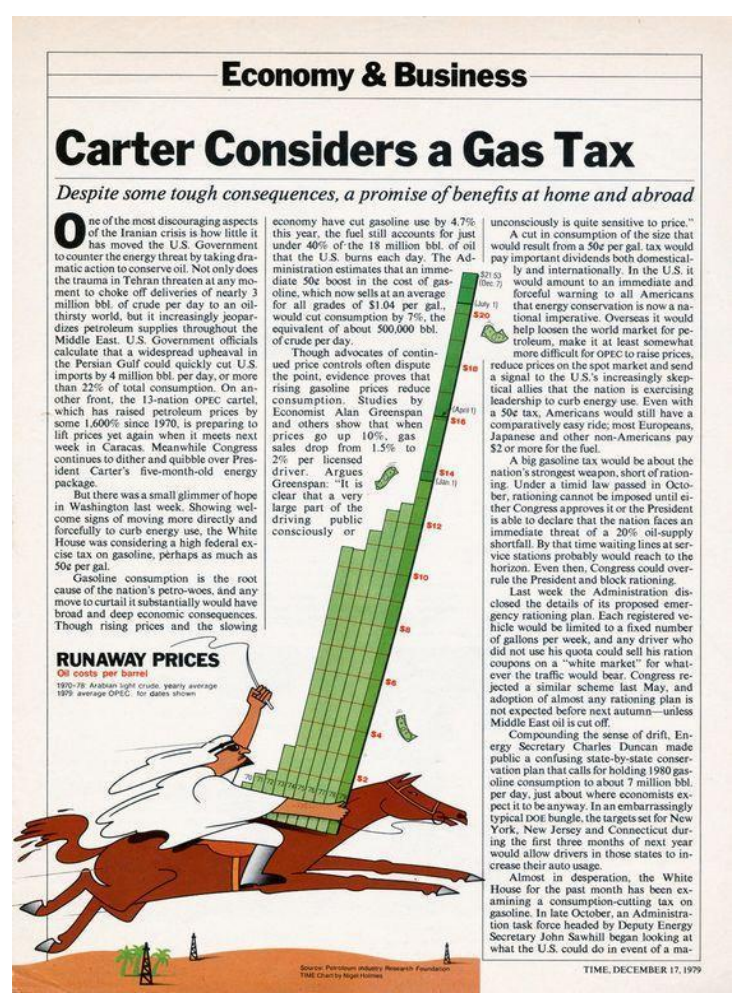

Os seus infográficos tiveram grande sucesso e Holmes ficou mundialmente conhecido nos anos em que trabalhou na revista Time (idem). Seu estilo foi copiado em praticamente todas as publicações jornalísticas da época que utilizavam gráficos, do jornal americano USAToday aos jornais brasileiros dos anos de 1980. Ele se tornou uma das maiores autoridades no campo e publicou manuais de design jornalístico e infografia, como Designer's Guide to Creating Charts \& Diagrams (1984) e Designing Pictorial Symbols (1985).

No entanto, esta grande difusão e influência do trabalho de Holmes também foi recebida com críticas, especialmente por acadêmicos. Lupton e Miller consideram que seus infográficos para revista Time poderiam ser vistos como "desenhos animados informativos para a era do "infotrenimento" (Lupton \& Miller, [1996] 2011:146). Podemos ver isso na maneira como Holmes estereotipou o Oriente Médio na Figura 1. Os autores se referem ao tratamento de Holmes em que imagem pictórica humorística "subjugava a estatística apresentada" (idem). Esta análise espelha uma crítica ainda mais deletéria do célebre teórico de design de informação, Edward Tufte $(1983,1990)$. Como veremos adiante, Tufte rejeitou a abordagem metafórica e humorística de Holmes por a considerar irresponsável. Para Tufte, os dados numéricos deveriam ser o foco da apresentação visual de gráficos estatísticos. Poderemos ver como a ideologia da neutralidade no design de informação, na forma do conceito de chartjunk, se direcionou ao trabalho de Holmes.

\section{Metáforas humorísticas vs neutralidade}

O objetivo da neutralidade é eliminar a presença do transmissor da mensagem. A crença é que a mensagem impessoal poderia neutralizar a manipulação retórica, preservando apenas a objetividade da informação. Edward Tufte está entre os autores que pregam a neutralidade do design da informação. Ele tem sido um dos teóricos mais influentes na promoção do uso de elementos esquemáticos estatísticos na infografia jornalística e vê semelhança entre o design da informação e os princípios universais da matemática que seriam independentes de contextos culturais (Carvalho \& Emanuel, 2015, p. 862). Em

Anais do 9ำ Congresso Internacional de Design da Informação । CIDI 2019 
The visual display of quantitative information (1983), Tufte considera essencial promover a informação com um alto índice de "data-ink" - termo que se refere à essência da mensagem a ser transmitida pela informação visual - algo que seja "não redundante" (ib). Na mesma obra, o autor cria o termo chartjunk para designar elementos gráficos que atrapalham a comunicação visual, ou seja, o oposto do conceito de data-ink. Para Tufte, chartjunk seria tudo que poderia ser caracterizado como elementos informacionais redundantes (FEW, 2011), uma forma de embelezamento supérfluo. Estes elementos se apresentam de várias maneiras: às vezes, como uma decoração artística e, frequentemente, na forma de elementos gráficos convencionais que, para ele, são desnecessários, na medida em que não agregam nenhum valor informacional. Segundo Tufte, o chartjunk não é informativo e, muitas vezes, é prejudicial (ib), afirmando que:

Por trás do chartjunk, há um desprezo tanto pela informação quanto pelo público leitor. Aqueles que promovem o chartjunk imaginam que os números são tediosos e chatos, exigindo ornamento para animá-los. [...] Se os números são chatos, então você tem os números errados. A credibilidade desaparece nas nuvens de chartjunk.

Este é um texto que lembra as críticas de Adolf Loos (1908) aos ornamentos do Art nouveau, Tufte fez críticas apaixonadas ao que considerava ser chartjunk na infografia e visualização de dados, revelando intolerância com a cultura popular daquela época: "quem confiaria em um gráfico que se parece com um videogame?" (Tufte, 1990).

O principal alvo de Tufte foram os trabalhos de Nigel Holmes da década de 1980, especialmente o seu uso de metáforas pictóricas em gráficos estatísticos. A Figura 2 mostra o gráfico "Diamantes foram o melhor amigo das moças" feito por Holmes, em 1982, para a revista Time (Bailey, 2014), utilizando metáforas pictóricas e o humor como recursos informacionais. Ao lado do gráfico de Holmes, Tufte incluiu um gráfico simples, apresentando apenas a informação esquemática e verbal, recomendando esta representação como a mais adequada. Como podemos ver, Tufte não tolera a tendência de Holmes de sobrepor elementos pictóricos aos elementos esquemáticos que formam o gráfico estatístico em seus infográficos. Iremos detalhar esta forma de linguagem gráfica, característica de Holmes, quando considerarmos os gráficos pictórico-esquemáticos.

Figura 2: Comparação de Tufte entre um gráfico pictórico de Nigel Holmes e outro não pictórico proposto por Tufte. Fonte: (TUFTE, 1983).

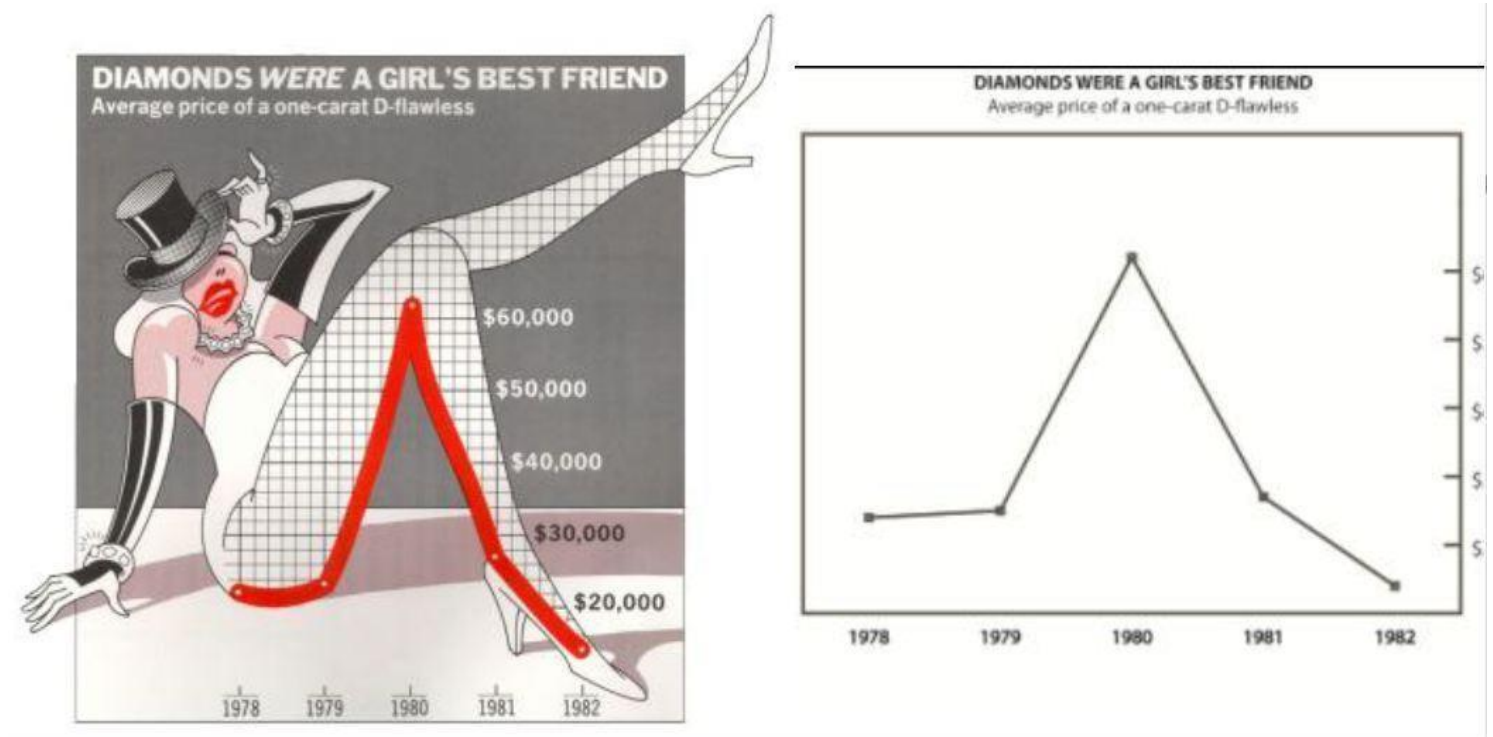

Ao longo dos anos, as críticas à infografia pictórica e o crescimento do uso da "visualização de dados" (ou "DataViz") estimularam os designers jornalísticos a valorizarem soluções de representação esquemática, utilizadas pelas ciências exatas. A preferência por um enfoque maior em soluções esquemáticas beneficiou o desenvolvimento de gráficos estatísticos mais

Anais do 9ำ Congresso Internacional de Design da Informação | CIDI 2019

Proceedings of the 9th Information Design International Conference

Anais do $9^{\circ}$ Congresso Nacional de Iniciação Científica em Design da Informação | CONGIC 2019

Proceedings of the $9^{\text {th }}$ Information Design Student Conference 
elaborados e complexos. No entanto, como colocam Carvalho e Emanuel (2015), a ideologia da neutralidade, que defende uma linguagem gráfica desprovida de ambiguidades ou ruídos informacionais, ignora diversos estudos de retórica e de filosofia da linguagem que consideram a neutralidade uma impossibilidade.

Vale salientar também que Holmes não propunha uma neutralidade em seus gráficos, mas, em contrapartida, podia incorporar explicitamente uma interpretação editorial problemática dos dados apresentados. Ele viveu a transição entre os chargistas editoriais, "de quem tradicionalmente se espera que expressem suas próprias opiniões" (idem), e os "jornalistas gráficos" cuja "função é expressar a opinião dos outros" (idem) através de levantamento de dados. A trivialidade temática de muitos dos seus gráficos reflete o "tipo de informação que os designers e ilustradores são chamados a representar" (idem).

Mas a preferência por gráficos mais alegres e superficiais foi diminuindo, ao longo do tempo, e Holmes começou a mudar a abordagem de muitos de seus trabalhos. Um exemplo disso é seu livro Wordless diagrams ("Diagramas sem palavras" [Holmes, 2005]). Na Figura 3, presente no livro, vemos como quatro nacionalidades (França, Rússia, Holanda e EUA) se beijam. Neste trabalho, o designer utiliza um tratamento mais sóbrio e um estilo de desenho figurativo mais geométrico, próximo do estilo gráfico usado em pictogramas. No entanto, a mudança de tratamento gráfico não deixa de ser menos humorística.

Figura 3: "Diagramas sem palavras" (Wordless diagrams). Fonte: (Holmes, 2005).
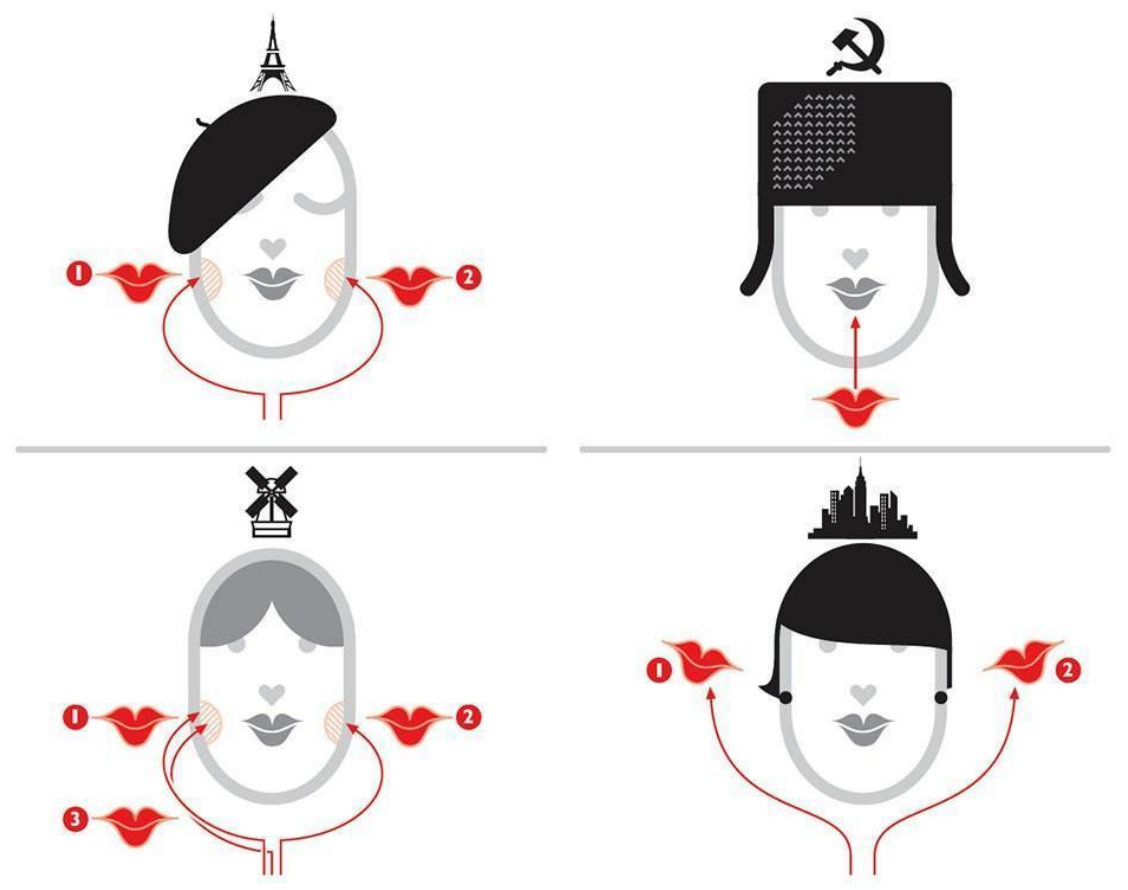

A chegada do século XXI trouxe o crescimento pela demanda por gráficos estatísticos complexos, fato que ajudou a popularizar o termo DataViz no design jornalístico. Um número cada vez maior de autores especializados em infografia voltada para dados numéricos seguiram os preceitos de Edward Tufte $(1984,1990)$. Entre eles, Alberto Cairo $(2008 ; 2013$; 2016) se destacou advogando que o jornalismo contemporâneo deveria focar na análise estatística como a base do trabalho investigativo jornalístico.

Na medida que a linguagem dos gráficos estatísticos não se limitou ao campo das ciências e passou a ser uma ferramenta essencial no design jornalístico, formas apropriadas de se criar gráficos começaram a ser discutidas com maior frequência. Neste cenário, o debate crítico sobre o chartjunk, levantado por Tufte (1990), se intensificou e Holmes teve que defender o seu trabalho, iniciando o Chartjunk Debate (Few, 2011).

Anais do 9ำ Congresso Internacional de Design da Informação | CIDI 2019 
Um dos principais problemas do argumento de Tufte (1984) (1990) sobre os elementos pictóricos metafóricos em gráficos, usados por Holmes e outros designers, é que se trata de uma conclusão que não é embasada em uma análise empírica. Em um estudo recente, Bateman (Bateman et al., 2010), decidiu testar as afirmações de Tufte, comparando os chartjunks pictóricos de Holmes com gráficos estatísticos sem complementação pictórica. A pesquisa de Bateman e de sua equipe consistiu em testes de compreensão e rememoração. $O$ resultado final da pesquisa demonstrou que os participantes identificaram as mensagens de valor numérico nos gráficos de Holmes, significativamente, mais vezes do que nos gráficos simplificados. Além disso, os participantes consideraram os gráficos de Holmes mais atraentes, mais divertidos e descobriram que eram mais fáceis e mais rápidos de lembrar (ib). A despeito destes estudos o termo chartjunk continua sendo utilizado na literatura de visualização de dados. Teóricos célebres no campo permanecem defendendo a sua validade, como o designer e professor norte americano, Stephen Few (2011), no artigo The Chartjunk Debate: a close examination of recent findings.

\section{A metáfora pela perspectiva cognitiva}

No final do século $X X$, a perspectiva cognitiva tornou-se o paradigma dominante em estudos de metáforas. O paradigma cognitivista pressupõe que, enquanto a maioria das metáforas se manifestam verbalmente, seria um erro equivaler estas manifestações verbais com seus originais cognitivos (Forceville, 2002). Como tais pressupostos sugerem que metáforas não se limitam à linguagem verbal, pesquisadores de diversos campos têm estudado a sua multimodalidade.

O linguista Charles Forceville (2008) ampliou os estudos das metáforas cognitivas, ao utilizar o conceito de metáforas multimodais, ou seja, de metáforas que podem se manifestar em diferentes canais e modos de simbolização, não apenas a linguagem verbal. Além de Forceville, pesquisadores têm estudado metáforas que não são limitadas ao âmbito verbal, como nos estudos de mídia, Nöel Carroll (2001), na visualização de dados, Isabel Meirelles (2007), na linguagem gráfica de diagramas, Clive Richards (1984) (2000), e no design de interfaces, Aaron Marcus (2002), entre outros. Quando os autores citados abordam a linguagem esquemática de gráficos estatísticos, ela tem sido conceituada como uma forma de metáfora. Ou seja, uma "barra" um gráfico é uma aproximação de um conceito, representa visualmente qualidades, não se trata de uma representação literal de algo concreto.

A publicação mais significativa nos estudos de metáforas cognitivas foi Metaphors we live by (1980), de George Lakoff e Mark Johnson. Neste livro, a metáfora não é apenas um problema limitado à imaginação poética, uma ornamentação estilística ou retórica, como tem sido tratada tradicionalmente. Para Lakoff \& Johnson, a metáfora está diretamente conectada ao dia a dia pelos pensamentos e ações. Nosso sistema conceitual cotidiano é fundamentalmente metafórico em sua natureza (idem). Segundo Lakoff (1980), "a essência da metáfora é a compreensão e a experiência de uma coisa em termos de outra", ou seja, uma analogia entre a coisa concreta (familiar e palpável) e outra mais abstrata (e menos conhecida). Dessa maneira, "transportamos" uma maneira de se relacionar em uma esfera da nossa vida para outra (idem).

Em Lakoff \& Johnson, esse processo de correspondência ocorre através do "mapeamento" entre os domínios semânticos: o domínio-fonte (mais concreto) e o domínio-alvo (mais abstrato). Se analisarmos a metáfora: "nosso namoro está em um beco sem saída", o que está sendo sugerido é o conceito metafórico de que O AMOR É UMA VIAGEM. O domínio alvo do AMOR (envolvendo a complexidade dos anseios dos amantes) é mapeado em termos do domínio-alvo da VIAGEM (que engloba aspectos concretos como o viajante, o veículo de transporte, os destinos, etc.). Neste exemplo, podemos pensar sobre o amor, utilizando o que conhecemos sobre jornadas. Na Figura 4, abaixo, vemos outro exemplo romântico: "o amor é fogo que arde", "o amor" é o domínio-alvo (abstrato) e se relaciona com o domínio-fonte "fogo que arde", que é mais concreto.

Anais do 9ำ Congresso Internacional de Design da Informação | CIDI 2019 
Figura 4: Exemplo de metáfora verbal. Fonte: diagrama do autor.

\section{Metáfora verbal: "o amor é fogo que arde"}

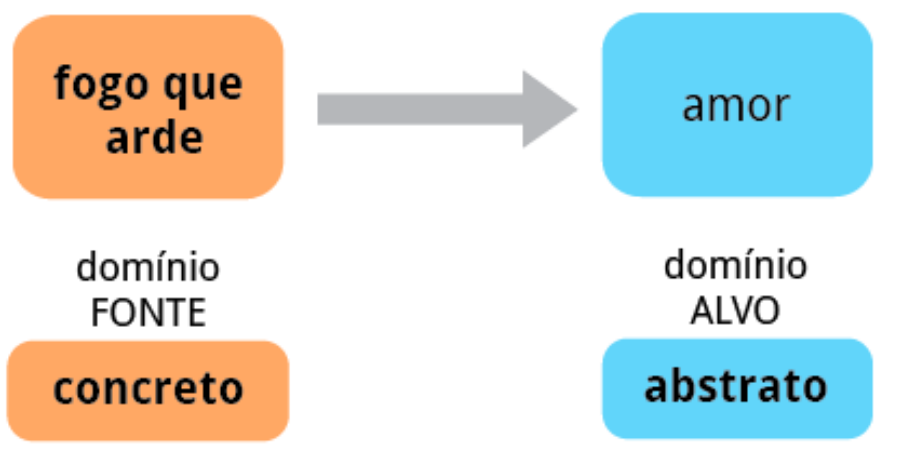

\section{As figuras de linguagem e as metáforas pictóricas de Nigel Holmes}

$\mathrm{Na}$ tese de doutorado, "A metáfora visual e enquadramento na infografia: o enfoque nos gráficos estatísticos" (Lima, 2018), analisamos e identificamos as figuras de linguagem mais comuns em infográficos contemporâneos (Tabela 1). Demos especial ênfase às figuras de linguagem pictóricas na infografia, isso é especialmente relevante, pois se costuma relacionar os gráficos à linguagem esquemática, considerando os elementos pictóricos como redundantes ou chartjunk. No entanto, na medida em que compreendemos a comunicação como um processo que depende do contexto cultural da audiência e do processo de enquadramento da informação, nos afastamos da ideia de neutralidade. Entendemos que ignorar a natureza retórica na linguagem é "um sonho impossível", como afirmou Bonsiepe (1965). 
Tabela 1: Taxonomia para compreensão da retórica pictórica de gráficos estatísticos. Fonte: (Lima, 2018).

Figura de linguagem pictórica Descrição
Exemplo na infografia e visualização de dados
Hipérbole O exagero de um objeto além do seu tamanho natural.

Amplificação Quantidade representada através da repetição ou enumeração de elementos.

Símile Analogia entre formas semelhantes.

Sátira Ridicularização de um tema, organização ou indivíduo, com um objetivo frequentemente humorístico, podendo incluir outras figuras de linguagem, como a ironia.

Antítese Oposição de idéias contrastantes.

Personificação Tipo de metáfora em que qualidades humanas são emprestadas a objetos inanimados.

Sinédoque A utilização de parte de um objeto ou / metonímia conceito para representar o seu todo.

Símbolo Metáforas ou sinédoques / metonímias que assumem um valor convencional
Quantidade numérica pela escala pictórica.

Semelhança entre elementos esquemáticos e pictóricos

Relacionar elemento pictórico com o contexto cultural do tema.

\section{Contraste cromático de categorias.}

Símiles com a função de personificação.

Elemento pictórico que representa uma categoria do tema abordado. Elementos essenciais da infografia, utilizados para pontuar conceitos e categorias.

Uma das características do trabalho Nigel Holmes é o uso extensivo de figuras de linguagem pictóricas. Segundo o próprio Holmes, sua motivação ao usar metáforas e a linguagem figurada foi tornar conceitos financeiros e comerciais mais acessíveis para os leitores leigos da revista Time (Heller, 2006).

O que segue são dois tipos de metáforas pictóricas utilizadas com frequência por Nigel Holmes em sua carreira: os gráficos pictórico-esquemáticos (equivalente à símile no contexto da teoria de figuras de linguagem) e a personificação (conhecida como metáfora ontológica pela linguística cognitiva).

\section{A símile e os gráficos pictórico-esquemáticos}

A símile pictórica se refere à analogia entre formas semelhantes. A símile verbal é uma metáfora que sugere uma analogia através das palavras "como" ou "tal qual" - a afirmação "bela como uma flor", por exemplo. No exemplo da Figura 5, um infográfico de Holmes que trata da estatística de virgindade em universidades, podemos ver claramente a símile pictórica através da semelhança entre as linhas de contorno dos corpos humanos como as linhas do gráfico. 
Figura 5: Exemplo de símile e gráfico pictórico-esquemático criado por Nigel Holmes, publicado na Glamour Magazine na década de 1980. Fonte: (GRIMWADE, 2016).

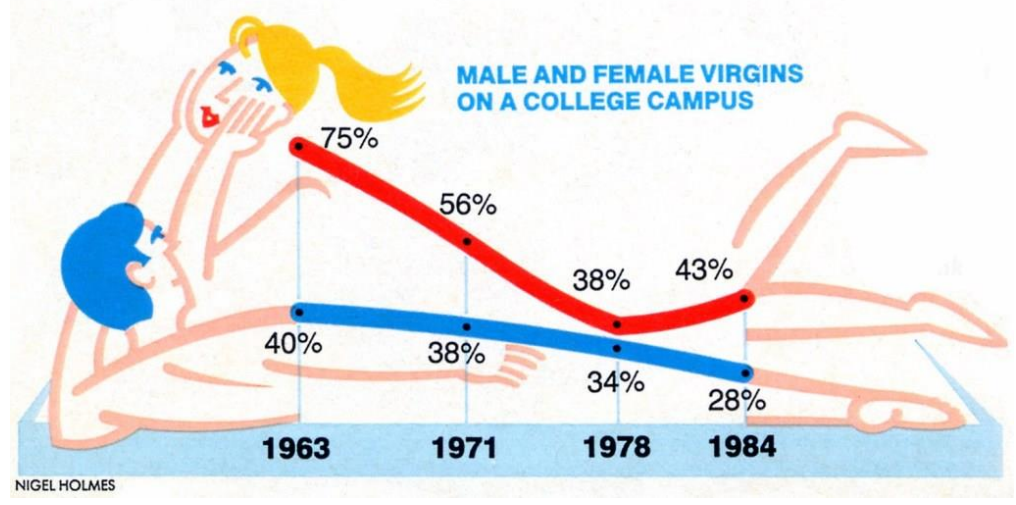

Como já mencionamos, em uma metáfora pictórica comum, a analogia ocorre através da semelhança conceitual entre o domínio-FONTE (concreto) e o domínio-ALVO (abstrato). No entanto, no caso da símile pictórica, por se tratar de semelhança visual, tanto o domínioFONTE quanto o domínio-ALVO são representados visualmente (Forceville, 2008). No caso de símiles utilizadas em gráficos estatísticos, percebemos uma tendência a se unificar os elementos esquemáticos (domínio-ALVO [abstrato]) com os elementos pictóricos (domínioFONTE [concreto]). Dessa maneira, o leitor tem acesso a metáforas simultaneamente pictóricas e esquemáticas em uma mesma imagem.

Se voltarmos ao exemplo acima, Figura 5, o domínio-FONTE são os jovens casais de estudantes, representados pela sensualidade das suas silhuetas, domínio-ALVO são as linhas do do gráfico. Ambos domínios são representados visualmente, mas o domínio FONTE, a sensualidade do casal, pode ser mais familiar ao leitor e o aproxima da natureza mais árida do gráfico estatístico, o domínio-ALVO.

O uso de símiles em gráficos estatísticos faz parte do que batizamos aqui de gráficos pictórico-esquemáticos. Isso ocorre porque pode ser difícil distinguir claramente entre as modalidades pictóricas e as esquemáticas. isto porque, para Twyman (1982), determinar o tipo de modalidade gráfica não depende apenas da imagem, mas pode estar relacionado com o usuário e a circunstância particular de uso. O esquemático e o pictórico podem se misturar, como vimos, na Figura 5, na união entre a linhas pictóricas do casal e as linhas esquemáticas do gráfico.

\section{Os gráficos pictórico-esquemáticos são aqueles em que os elementos pictóricos se sobrepõem à estrutura esquemática de um gráfico estatístico.}

Vemos isso, claramente, nos gráficos criado por Holmes (ver Figura 2 e 5): a figura à esquerda é uma versão pictórica do gráfico esquemático à direita. Essa fusão de modalidades gráficas faz com que o gráfico de Holmes ofereça uma dupla função. Através de metáforas pictóricas (o monstro e seus dentes), os custos são relacionados a uma hipérbole de monstruosidade. Através das metáforas esquemáticas (o gráfico de barras formado pelos dentes), dados quantitativos representam os valores numéricos dos custos. 
Figura 5: Gráfico pictórico-esquemático criado por Nigel Holmes. À direita, uma versão do mesmo gráfico sem os elementos pictóricos criado pela equipe de Bateman. Fonte: (Bateman, 2010).
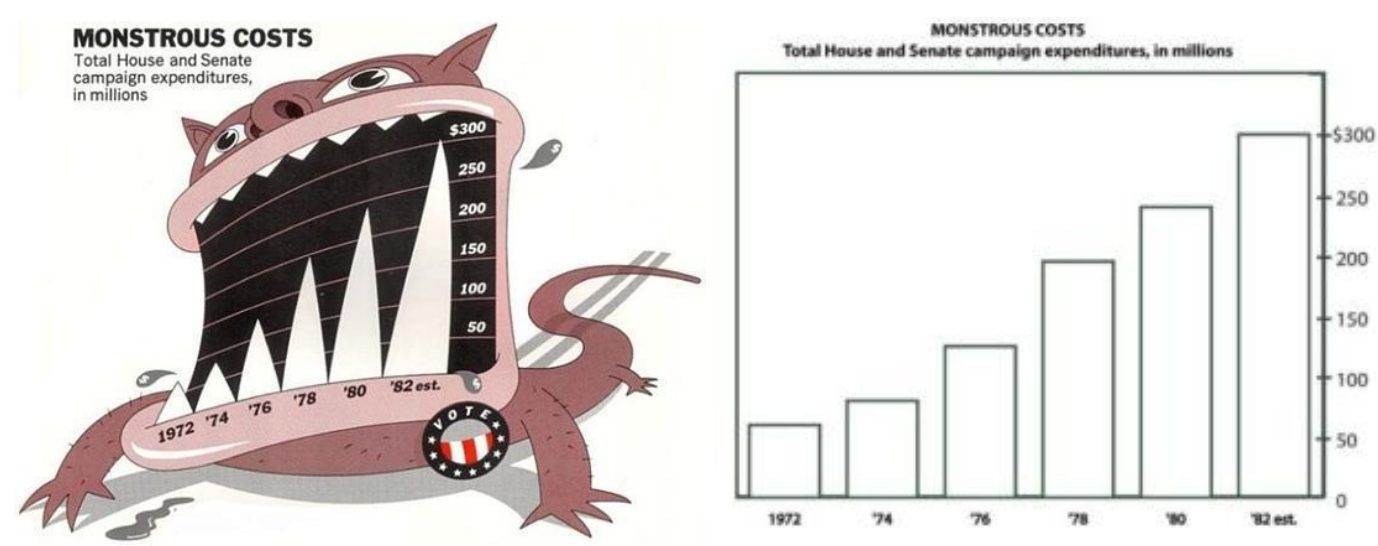

Muitos trabalhos de Holmes são gráficos pictóricos-esquemáticos. Estas modalidades gráficas são símiles em sua essência, pois relacionam metáforas pictóricas a dados estatísticos esquemáticos através da sua semelhança gráfica.

A Figura 6, seguinte, mostra o gráfico "Diamantes foram o melhor amigo das moças" feito por Holmes, em 1982, para a revista Time (Bailey, 2014), no qual descreve a queda do preço dos diamantes, utilizando a representação cartunesca de uma mulher. Além disso, Holmes utiliza símiles gráficas para unir a informação pictórica à esquemática: as pernas da mulher sugerem as linhas de um gráfico de linha e a textura quadriculada, semelhante a uma meia "arrastão", tem o significado metafórico da precisão dos números estatísticos. Trata-se de um gráfico que, através do tipo de representação pictórica e o título humorístico, ironiza os fatos representado pelos dados estatísticos.

Figura 5: Gráfico de Nigel Holmes e a análise pictórica do mesmo. Fonte: <nigelhomes.com>.
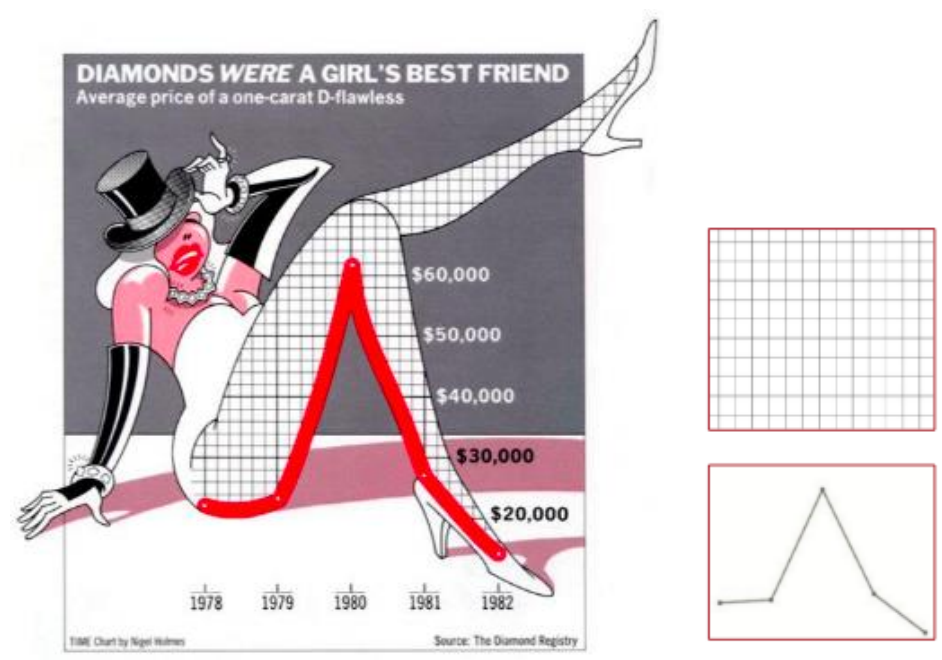

Meia "arrastão" como papel quadriculado: precisão dos números estatísticos

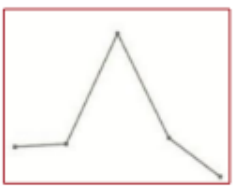

Pernas como

gráfico de linha

\section{A personificação (Metáfora Ontológica)}

A personificação é um tipo de metáfora em que qualidades humanas são emprestadas a objetos inanimados (Ehses, 1984). Um exemplo é a expressão verbal: "o celular morreu". Literalmente, nada está morto, mas se considerarmos metaforicamente o celular como uma entidade viva, a descarga de sua bateria configura um tipo de morte.

Anais do 9ำ Congresso Internacional de Design da Informação | CIDI 2019

Proceedings of the 9th Information Design International Conference

Anais do $9^{\circ}$ Congresso Nacional de Iniciação Científica em Design da Informação | CONGIC 2019

Proceedings of the $9^{\text {th }}$ Information Design Student Conference 
Lakoff \& Johnson (1980) consideram a personificação um tipo de metáfora ontológica. Como foi dito, o ser humano se relaciona com o ambiente através de relações corpóreas, por isso concebemos experiências como objetos ou substâncias. Dessa maneira, podemos categorizá-las, agrupá-las, quantificá-las, etc. Portanto, metáforas representam eventos, atividades, emoções e ideias como entidades e substâncias. Quando afirmamos que a "inflação está baixando o padrão de vida", além da evidente metáfora orientacional (ACIMA é bom, ABAIXO é ruim), estamos tratando a "inflação" como uma entidade física e não apenas como um fenômeno econômico. O exemplo citado é uma forma de "personificação", uma conhecida figura de linguagem e um tipo comum de metáfora ontológica. Outros exemplos comuns são: PALAVRAS SÃO RECIPIENTES, evidenciado na expressão "essas são palavras vazias" ou a MENTE É UM RECIPIENTE: "não consigo tirar essa música da minha mente", "minha mente está vazia" e "ela (a mente) é cheia de boas ideias".

A metáfora nos ajuda "a compreender parcialmente o que não pode ser totalmente compreendido" (Lakoff \& Johnson, 1980) através de uma analogia entre o concreto e o abstrato. Portanto, ao imbuirmos dados numéricos abstratos (pouco acessíveis a leigos) de qualidades humanas concretas, enquadramos a narrativa do infográfico dentro de um cenário reconhecível a um leitor comum.

Na Figura 7, abaixo, vemos um infográfico em que Holmes lança mão da personificação para mostrar diferentes percentuais dos custos médicos nos Estados Unidos e transforma gráficos de barra em entidades vivas: pacientes deitando em camas de hospital. Como explica o próprio Holmes (1984), "com as barras deitadas nas camas, uma impressão visual imediata de [...] custo é dada". Metáforas permeiam esse gráfico, a escolha das camas antigas ("vitorianas") reflete a intenção de torná-las mais reconhecíveis (logo, mais concretas) para o leitor. Como afirma Holmes, seria "mais confuso" para o leitor se as camas fossem desenhadas "como são de verdade" (idem).

Figura 7: Infográfico de Nigel Holmes. Fonte: <www.nigelholmes.com>.

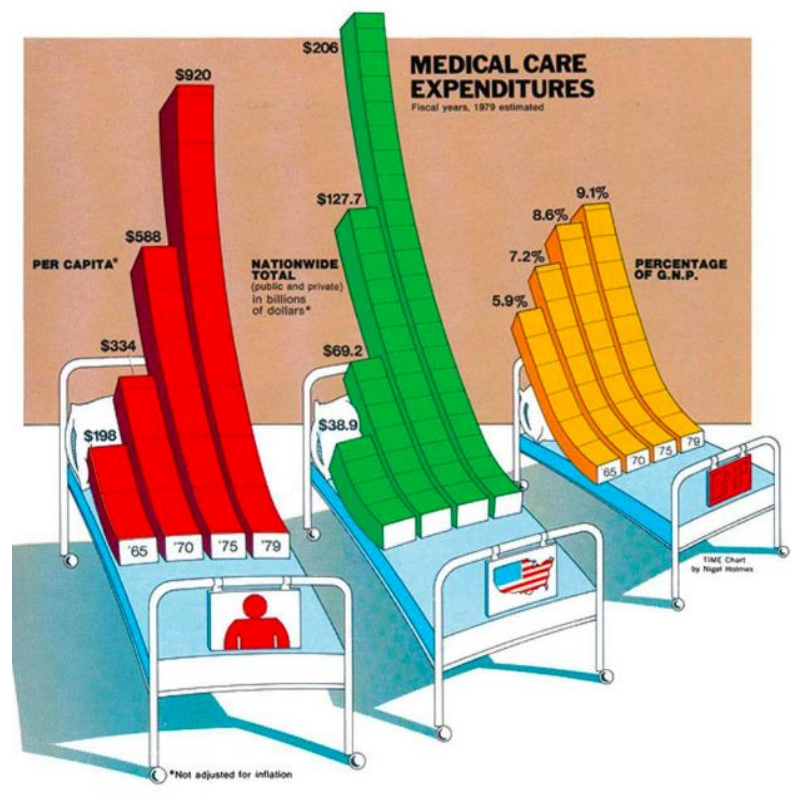

\section{Conclusão}

Podemos ver que a relevância de se procurar explicações visuais se revela quando pensamos em fatos e explicações complexas que precisam ser comunicadas e contextualizadas. Assim, o objetivo das explicações através visualização de dados e infografia não é apenas tornar a informação jornalística mais atrativa, mas também auxiliar o leitor a compreender algo que,

Anais do 9ำ Congresso Internacional de Design da Informação | CIDI 2019 
comunicado de outra maneira, poderia parecer complexo demais. A metáfora visual tem sido um ferramenta essencial neste sentido, pois nos ajuda a compreender algo através de uma analogia entre o concreto e o abstrato (LAKOFF \& JOHNSON, 1980). Logo, ao imbuirmos dados numéricos (pouco acessíveis a leigos) de qualidades humanas e concretas, enquadramos a narrativa dentro de um cenário reconhecível para o leitor. Os gráficos metafóricos de Holmes são voltados para públicos específicos e eles contribuem para determinar como a publicação dialoga com o público que pretende atingir. Os leitores, por sua vez, lêem, em diferentes contextos e com diferentes expectativas, a informação a ser consumida.

Nos últimos anos, Holmes tem falado dos seus gráficos do começo de carreira com um olhar crítico, mas continua advogando a importância de se valorizar o humor como uma ferramenta de comunicação.

Recentemente, mais infografistas têm explorado o caminho trilhado por Holmes. No campo da infografia em vídeos online, o grupo alemão Kurzgesagt (Figura 8, à esquerda) tem criado animações, tratando de assuntos políticos, filosóficos e científicos, com um desenho vetorial simples e cartunesco. No campo da infografia estática publicada nas redes sociais, o grupo mexicano Pictoline (Figura 8, à direita) cria explicações pictóricas em diversos estilos cartunescos. Eles costumam seguir a configuração sequencial das histórias em quadrinhos para abordar temas jornalísticos atuais e científicos. Ambos os grupos utilizam o humor, a cultura popular, gráficos pictórico- esquemáticos e figuras de linguagem visual para explicar assuntos pouco familiares para o público em geral.

Figura 8: Animação "O que é você?" do Kurzgesagt (à esquerda). "O que veio primeiro?" da Pictoline (à direita). Fontes: <kurzgesagt.org $>$ e <pictoline.com>.
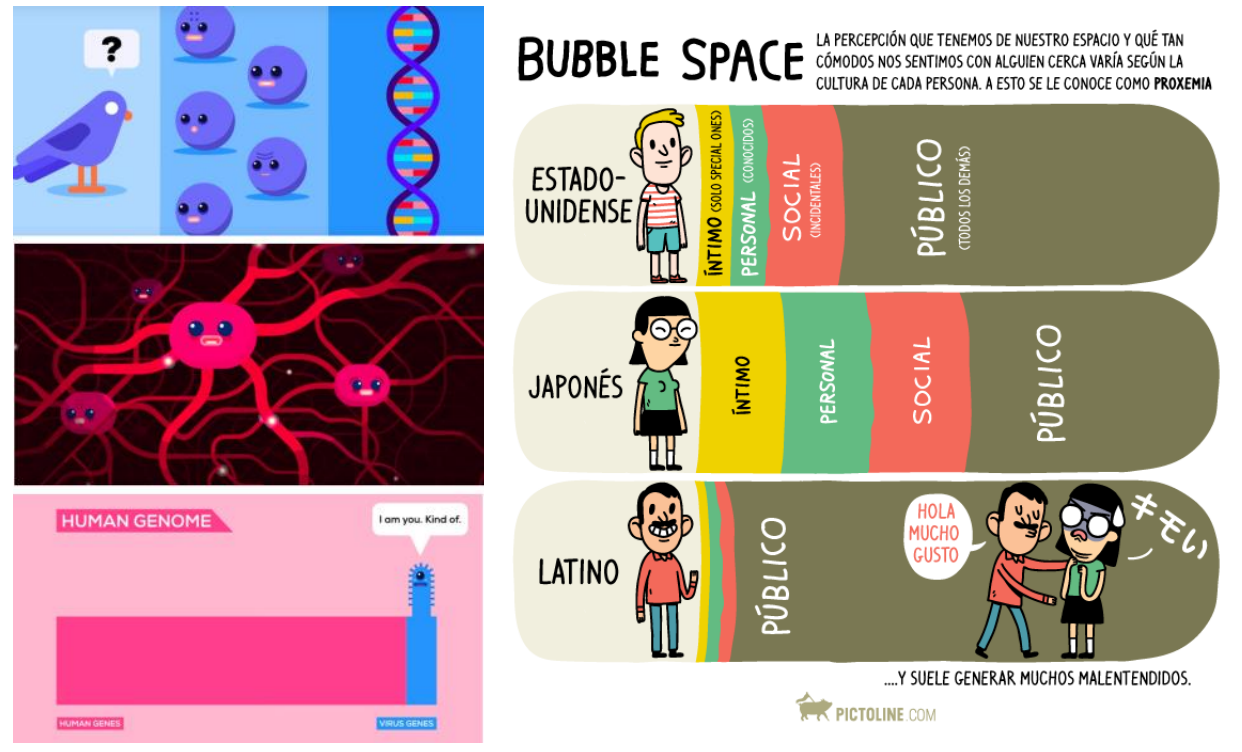

Na própria obra recente de Holmes, vemos que o designer continua associando elementos pictóricos aos esquemáticos em visualizações de dados para facilitar a compreensão e engajamento do leitor. Como podemos ver no infográfico "Vampire Energy", publicado em 2008 para o website "Good" (Figura 9). A principal conclusão que tiramos dos argumentos de Holmes é que seu trabalho é voltado para públicos específicos e contribuem para determinar como a publicação dialoga com o público que pretende atingir. Por exemplo, a informação visual terá uma abordagem retórica diferente se estivermos lidando com leitores versados nas ciências exatas ou economia e outros leitores que não são familiarizados com estes conhecimentos.

Anais do 9ำ Congresso Internacional de Design da Informação | CIDI 2019 
Figura 9: Infográfico "Vampire Energy" de Nigel Holmes. Fonte: <www.good.is>.

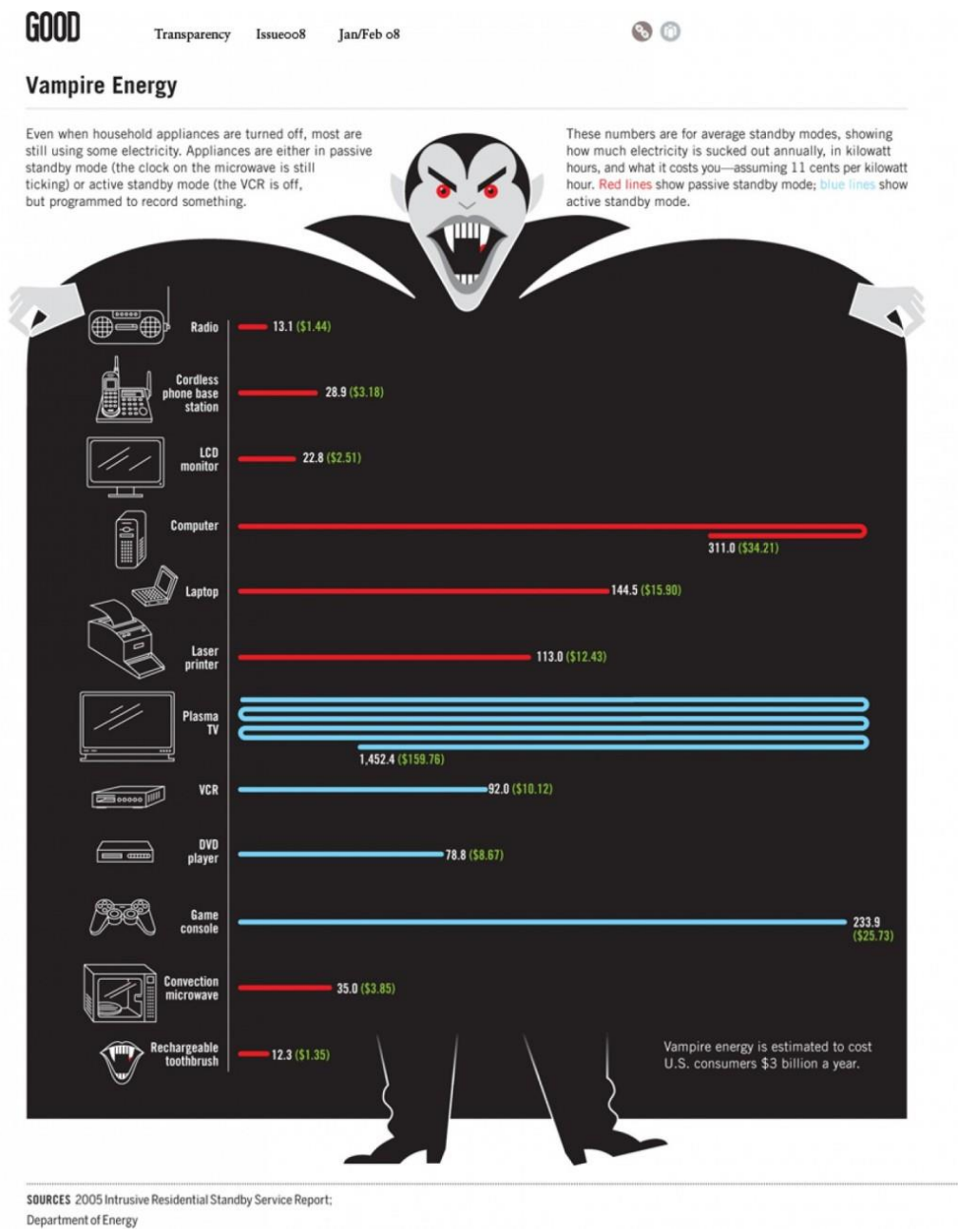

O designer de informação deve estar atento ao fato de que a linguagem esquemática é parte do currículo acadêmico, comum a diversos cursos universitários, e está presente em programas digitais de visualização de dados. No entanto, um público que não teve esse tipo de formação, se beneficia com uma abertura maior na abordagem retórica. Saber distinguir o tipo de enquadramento que atenda às especificidades do seu público é uma habilidade essencial para o êxito de um projeto infográfico.

Por isso, consideramos que o debate sobre o chartjunk precisava ser levantado neste estudo. Já adiantamos que a literatura básica de design de informação sugere que as metáforas pictóricas são meros embelezamentos redundantes. Procuramos demonstrar que esta convicção é infundada. Metáforas pictóricas apresentam várias funções comunicacionais, entre elas se destacam a contextualização e o esclarecimento de um assunto complexo. $O$ termo chartjunk, usado por Tufte para metáforas pictóricas em gráficos (1990), é inadequado.

A tradição crítica aos elementos pictóricos vistos como redundantes à funcionalidade do design tem se mostrado limitadora à compreensão da linguagem gráfica. A redundância neste caso, seria a repetição dos dados esquemáticos numéricos associados a uma representação pictórica, sendo essa última o foco da crítica. Como consequência desta oposição, tem havido uma progressiva padronização de projetos de infografia e visualização de dados influenciados por manuais que defendem essa ideia e que são utilizados por profissionais do campo.

Procurei demonstrar que o discurso da redundância e embelezamento, como tem sido apresentado por Tufte, não tem fundo empírico, tratando-se antes de convicções sem base científica. Devemos lembrar que uma das bases do design editorial é a redundância, a

Anais do 9ำ Congresso Internacional de Design da Informação | CIDI 2019

Proceedings of the 9th Information Design International Conference

Anais do $9^{\circ}$ Congresso Nacional de Iniciação Científica em Design da Informação | CONGIC 2019

Proceedings of the $9^{\text {th }}$ Information Design Student Conference 
repetição padronizada dentro da grid tipográfica. Um leitor espera que um número da página esteja na mesma posição. Portanto, a redundância que Tufte denúncia existe, mas sem a carga negativa apontada por ele.

Por outro lado. no ensino do design há pouca discussão sobre as funções retóricas de conceitos fundamentais utilizados diariamente por infografistas e designers gráficos. Conceitos como literalidade e neutralidade são tomados ao pé da letra, sem uma abordagem mais crítica. Este aspecto da formação dos responsáveis pela criação de infográficos facilita a adesão acrítica aos princípios comentados aqui.

No mundo onde a visualização de dados se torna uma tendência cada vez mais importante e presente, a compreensão do papel da metáfora é uma chave para comunicação com um público não especializado. Quando o infografista se lança na aventura de trabalhar com metáforas visuais, se tem a coragem de enfrentar esse desafio, poderá alcançar uma dimensão subjetiva mais ampla.

\section{Referências}

Bailey, J. (2014) Speak to the Eyes: The History and Practice of Information Visualization. 2014. Disponível em: <http://goo.gl/wlsR7V>. Acesso em: 20 jan. 2016.

Bateman, S., et al. (2010). Useful Junk? The Effects of Visual Embellishment on the Comprehension and Memorability of Charts. In: the Proceedings of ACM Conference on Human Factors in Computing Systems (CHI 2010), pp. 10-15.

Bonsiepe, G. (1999). Visual/verbal Rhetoric. In: M. Bierut, J.; Helfand; S. Heller and R. Poynor (eds.) Looking Closer 3: Classic writings on graphic design. pp. 167-173. Allworth Press.

Carroll, N. (2015) Introducing Visual Metaphor. In: Beyond Aesthetics: Philosophical Essays. University of Wisconsin, Madison: Cambridge University Press, 2001. CARVALHO, Ricardo Artur Pereira; EMANUEL, Bárbara. Linguagem e Design: sobre a impossibilidade da neutralidade da informação, p. 855-868. In: Anais do 7º Congresso Internacional de Design da Informação| CIDI 2015 [Blucher Design Proceedings, num.2, vol.2]. São Paulo: Blucher.

Few, S. (2011). The Chartjunk Debate: a close examination of recent findings. In: Visual Business Intelligence Newsletter, 2011. Disponível em: <http://goo.gl/uARrV <. Acesso em 12 janeiro 2016.

Forceville, C. "Further Thoughts On Delimiting Pictorial Metaphor. In: Theoria et Historia Scientiarum 6:1, 213-27. (Nicolaus Copernicus UP, Toruń, Poland). 2002. Metaphor in pictures and multimodal representations. In: Raymond Gibbs, Jr. (ed.), The Cambridge Handbook of Metaphor and Thought. Cambridge: Cambridge University Press, 462-482. 2008.

Ehses, H. (1984). Representing Macbeth: A Case Study in Visual Rhetoric. Design Issues, v. 1, n. 1 , p. 53-63, 1984.

Grimwade, J. (2016). Nigel Holmes On Humor: A Warmer Approach to Infographics, 2016.

Disponível em: <https://www.johngrimwade.com/blog/2016/10/03/nigel-holmes-onhumor>. Acesso em 25 janeiro 2018.

Lakoff, G., \& Johnson, M. (1980). Metaphors We Live By. University of Chicago Press.

Lima, R. C. (2009). Análise da infografia jornalística. 2009. 143 f. Dissertação de Mestrado em Design, Escola Superior de Desenho Industrial (ESDI/UERJ), Rio de Janeiro.

Anais do 9 Congresso Internacional de Design da Informação | CIDI 2019 
O que é infografia jornalıstica?' Revista InfoDesign, 12(1), 2015, pp. 111-127.

. A metáfora visual e enquadramento na infografia: o enfoque nos gráficos estatísticos. 2018. 191f. Tese (Doutorado em Design) - Escola Superior de Desenho Industrial (ESDI/UERJ), Rio de Janeiro, 2018.

Marcus, A. (2002). Metaphors and User Interfaces in the 21st Century. Interactions, 9(2).

Meirelles, I. (2013). Design for information: an introduction to the histories, theories, and best practices behind effective information visualizations. Rockport.

Heller, S. (2006). Nigel Homes on Information Design. Nova lorque: Jorge Pinto Books.

Holmes, Nigel. Designer's guide to creating charts and diagrams. Nova lorque: Watson- Guptill, [1984] 1991.

Designing pictorial symbols. Nova lorque: Watson-Guptill, 1985.

Wordless Diagrams. Nova lorque: Bloomsbury, 2005.

Richards, C. Diagrammatics: an investigation aimed at providing a theoretical framework for studying diagrams and for establishing a taxonomy of their fundamental modes of graphic organization. Londres: Royal College of Art, 1984. Getting the Picture: diagrams design and the information revolution. Information Design Journal, 9(2/3), p. 87-110. 2000.

Twyman, M. (1979). A Schema for the Study of Graphic Language. KOLERS, P.A. \& WROSTAD, M.E. \& BOUMA, H. (Eds.), In: The Processing of Visible Language, vol. 1, Plenum, New York, pp. 117- 150.

\section{Sobre o autor}

Ricardo Cunha Lima, Doutor em Design, UFPE, Brasil, <rcunhalima@gmail.com> 